\title{
Verryking as 'n leksikografiese prosedure
}

\author{
Rufus H. Gouws \\ Departement Afrikaans en Nederlands, Universiteit Stellenbosch, Privaat Sak X1, Matieland 7602, Suid-Afrika \\ E-pos: rhg@sun.ac.za
}

\begin{abstract}
In metalexicography the term "enriched item" refers to a dictionary item of which the centre has been expanded, i.e. enriched, by other item parts so that a new complex item is established as topic. This paper provides a brief discussion of the prevailing notion of enrichment. It is then indicated that the lexicographic practice has already increased the scope of this procedure, albeit that these innovations have not yet sufficiently been described in metalexicographic work. The lack of a theoretical discussion often leads to a haphazard application of enrichment where this procedure is not optimally employed. A classification is given of different procedures of enrichment, allowing a distinction between data-homogeneous and data-heterogeneous enrichment. These procedures can present examples of either single or double enrichment. It is shown that enrichment does not only target a single item but also an article zone where the procedure of enrichment can add another item, representing either the same or a different data type, to complement the original item. A typological distinction is made between enrichment aimed at expanding the data transfer in a dictionary article, enrichment aimed at enhancing the access in a dictionary and enrichment aimed at adding to the lexicographic functions. This last type is discussed with reference to the addition of the cognitive function in a dictionary with communication as primary function. The paper argues in favour of an even closer relation between lexicographic theory and practice, which will lead to a better description of enrichment but also a better application of this lexicographic procedure.
\end{abstract}

Keywords: data-heterogeneous enrichment, data-homogeneous enrichment, enrichment, function enrichment, pragmatic enrichment

\section{Inleiding}

In die leksikografiepraktyk word bepaalde prosedures soms gevolg omdat dit die natuurlike, die tradisionele of die bekende is - of dalk selfs omdat dit die regte ding is om te doen. Leksikograwe kan nie altyd 'n teoretiese verklaring gee vir 'n bepaalde prosedure nie en dikwels het leksikograwe geen behoefte aan of belangstelling in so 'n teoretiese verklaring nie. Leksikografie is 'n voortgaande en dikwels herhalende aktiwiteit en tydens 'n volgende siklus of opdrag mag dit nodig wees om dieselfde onverklaarde prosedure weer te volg. Die praktiserende leksikograaf mag dan al daarvan vergeet het, mag probeer om die noodsaak daarvoor te ignoreer, mag probeer om dit te onthou of selfs om daarop te verbeter. Een van die talle voordele van teoreties gebaseerde werk en die benutting van 'n teoretiese model is dat dit 'n stel riglyne bied wat toegepas, aangepas of geïgnoreer kan word tydens die fases van 'n 
leksikografiese proses waar die konseptualiseringsplan vir 'n nuwe woordeboek geformuleer word, of wanneer 'n woordeboek hersien of nuut saamgestel word. Dit maak leksikograwe dikwels bewus van verskillende moontlike werkswyses - hetsy gevestigde prosedures of innoverende moontlikhede wat nog beproef moet word. Dit is daarom belangrik dat alle prosedures wat in die leksikografiese praktyk tydens 'n leksikografiese proses (vgl. Gouws 2001, 2001a vir 'n bespreking van leksikografiese prosesse) gevolg moet word, beskryf word binne die raamwerk van 'n algemene leksikografieteorie. Hierdie beskrywing moet toeganklik wees vir daaropvolgende woordeboekprojekte, maar ook vir voortgesette teoretiese besinning.

Uit 'n oorsig oor die geskiedenis van die verhouding tussen leksikografieteorie en die leksikografiepraktyk is dit gou duidelik dat hierdie verhouding van 'n tweerigtingaard is teorie beïnvloed praktyk en praktyk beïnvloed teorie. In die oorgrote meerderheid gevalle is daar egter bewys dat die teorie eerder die praktyk gevolg het, deur dit te beskryf wat in die praktyk gebeur het eerder as om vernuwende idees ter verbetering van die praktyk daar te stel. Leksikografieteorie was te dikwels 'n volgeling eerder as 'n leier.

In hierdie bydrae is die fokus op een tipe leksikografiese prosedure wat gereeld in die woordeboekpraktyk gevolg word (alhoewel dikwels op 'n arbitrêre manier) maar waar die leksikograaf nie altyd daarvan bewus is dat 'n spesifieke prosedure gevolg word of dat die prosedure en sy gebruik reeds vanuit 'n teoretiese perspektief beskryf is en verder beskryf kan word nie. Deur van hierdie prosedure bewus te wees, is dit moontlik om die toepassing daarvan te verbeter. Dit help ook teoretiese leksikograwe om die beskrywing daarvan te verfyn en sodoende die moontlikheid te skep om die gehalte van die leksikografiese praktyk verder te verhoog. Die prosedure wat hier bespreek gaan word, staan in die leksikografieteorie bekend as verryking en die toepassing daarvan lei tot die skep van verrykte woordeboekinskrywings (vgl. Wiegand et al. 2010). Die metaleksikografie bied nog min besprekings van verryking as 'n leksikografiese prosedure. In hierdie bydrae word die term "verryking" gebruik met inagneming van sommige aspekte wat reeds aandag gekry het, maar daar word ook 'n uitbreiding van die bestek van hierdie prosedure voorgestel.

\section{Verrykte aanduiders}

In die teoretiese leksikografie word die term verrykte aanduider gebruik om te verwys na 'n woordeboekaanduider waarvan die kern uitgebrei (verryk) is deur ander aanduiderdele sodat 'n komplekse aanduideronderwerp tot stand kom. In die Oxford Reference Dictionary sluit die artikel van die lemmateken Chagall die volgende inskrywings in:

Chagall ... Russian-born painter, of Jewish family, who ...

Chagall was 'n skilder en in hierdie gedeelte van die leksikografiese definisie kan die aanduiderdeel painter beskou word as die kernnaamwoord waarmee die lemmateken beskryf word. Die voorafgaande inskrywing Russian-born en die daaropvolgende bepaling of Jewish family verryk die beskrywing en verander die enkelaanduider painter in 'n komplekse aanduider Russian-born painter, of Jewish family. Die enkelbetekenisaanduider painter word verryk en word nou slegs 'n aanduiderdeel wat saam met ander aanduiderdele bydra tot die spesifieke oordrag van data, bewerkstellig deur die komplekse betekenisaanduider. Indien hierdie verrykende aanduiderdele almal bydra tot 'n uitbreiding in die oordrag van betekenis, lei dit tot 'n semanties verrykte betekenisaanduider. 
'n Belangrike vraag hier behels die omvang van aanduiders in die betekenisparafrase, m.a.w. hoeveel data moet verstrek word, hoe ingrypend mag die verryking wees en wanneer oortree die leksikograaf die grense van die toelaatbare. 'n Woordeboek behoort altyd daarop gerig te wees om te reageer op die behoeftes en naslaanvaardighede van 'n duidelik geïdentifiseerde teikengebruikersgroep, en om een of meer leksikografiese funksies te bevredig. Dit impliseer dat verskillende woordeboeke verskillende, uiteenlopende betekenisparafrases vir 'n ooreenstemmende lemmateken sal aanbied. Vergelyk in hierdie verband die betekenisparafrase vir een van die betekenisonderskeidinge van die woord bridge in verskillende woordeboeke, soos gegee in (2):

\section{(2) a. a road or railway line built over something (Longman Mini English Dictionary) \\ b. a structure providing passage over a river, etc. (Random House Dictionary) \\ c. a road built over a river or a railway (Chambers-Macmillan South African Dictionary. Junior Primary) \\ d. a road or path built over a river or railway line or above another road (Shorter English Learner's Dictionary) \\ e. a structure carrying a road, path, railway, etc. across a river, ravine, road, railway or other obstacle (New Oxford Dictionary of English)}

Die tipe woordeboek bepaal die omvang van die betekenisaanduider en die behoeftes van die gebruiker behoort die aard van die betekenisbewerking wat gevolg word, te bepaal. Alhoewel die bondigste definisie voldoende mag wees vir die teikengebruiker van 'n spesifieke woordeboek word die omvattender definisies aangebied om die spesifieke behoeftes van die spesifieke teikengebruikers van daardie woordeboeke te bevredig. Alhoewel verryking tipieserwys binne 'n enkele woordeboek geld met betrekking tot die uitbreiding van die verstek-aard en -omvang van 'n aanduider (d.w.s. 'n afwyking van die verpligte mikrostruktuur) kan die begrip van verryking ook gebruik word in 'n vergelyking van een bepaalde aanduidertipe in verskillende woordeboeke, soos blyk uit voorbeeld (2). Die primêre fokus in hierdie artikel is op verrykingsprosedures binne een woordeboek.

Met verwysing na 'n veel ouer debat in die metaleksikografie kan die tipe semantiese verryking soos in voorbeeld (2) die vraag heraktiveer na die onderskeid tussen semantiese en ensiklopediese data, en hoeveel ensiklopediese data toelaatbaar is in 'n woordeboekdefinisie. Dit moet benadruk word dat dit 'n linguistiese en nie 'n leksikografiese onderskeid is nie. Die onderskeid tussen linguistiese en ensiklopediese data is leksikografies irrelevant. Wat hier leksikografies ter sake is, is die omvang van die data-aanbod, maar die motivering daarvoor het niks daarmee te make of dit linguistiese of semantiese data is nie (vgl. Bergenholtz en Gouws 2007). Wat belangrik en leksikografies ter sake is, is veel eerder die vraag na wat nodig is om die behoeftes van die geïdentifiseerde teikengebruiker te bevredig, en om dan so veel of so min data te gee as wat nodig is om 'n suksesvolle woordeboekraadplegingsprosedure te verseker. Verryking help met uitbreidings, ook in die betekenisaanduider, wat die gehalte van die data-oordrag in 'n woordeboek kan verhoog.

Die vroeë gebruik van verrykte aanduiders het veral voorgekom in woordeboeke waarin persoonsname en eiename bewerk is (bv. Bläsi 1998 en Wiegand 2005). Om in so 'n woor'deboek 'n suksesvolle bewerking te verseker van lemmatekens soos Napoleon, Shaka, Miriam Makeba en Breyten Breytenbach vereis die gebruik van verrykte aanduiders, sodat al daardie data wat nodig is vir 'n omvattende onttrekking van inligting, verstrek kan word. In 
hierdie woordeboeke is die prosedure van verryking meestal toegepas op soortgelyke aanduidertipes in vaste artikelgleuwe toegeken aan die spesifieke aanduidertipes. Die verrykte inskrywings het tipieserwys aanduiders verteenwoordig wat die betekenis van die lemmateken verstrek het.

Die prosedure van verryking strek verder as semanties verrykte aanduiders. Hierdie prosedure word ook toegepas op ander aanduidergleuwe as dié waarin die betekenisparafrase aangebied word. Die bewerking in die Longman South African School Dictionary sluit dikwels leiding in oor die herkoms van woorde. Hierdie inskrywings wissel in omvang vanaf 'n enkele woord wat slegs die taal van herkoms aandui, tot 'n aanduiding van die herkomsdatum, die oorspronklike betekenis en selfs die gebruik van die betrokke woord. Vergelyk voorbeeld (3), waar (3b-e) verskillende grade van verryking in die artikelgleuf vir woordherkoms aanbied, terwyl (3a) die minimum herkomsdata bied - die tipe aanduider wat 'n kandidaat is vir ' $n$ verrykingsprosedure.
a. marimba [Origin: Kimbundu]
b. inkosi [Origin: an Nguni word] <sintaktiese verryking van inskrywing >
c. recent: [Origin: $15^{\text {th }} \mathrm{C}$ Latin recens] $<$ verryking t.o.v. dagtekening en oorspronklike vorm>
d. $\quad$ stupid [Origin: $16^{\text {th }} \mathrm{C}$ Latin stupidus meaning "amazed, stunned"] < verryking t.o.v. dagtekening, oorspronklike vorm en betekenis van oorspronklike vorm>
e. Pope [Origin: $9^{\text {th }} \mathrm{C}$ Greek papas meaning "father", used as a title of bishops] $<$ verryking t.o.v. dagtekening, oorspronklike vorm, betekenis van oorspronklike vorm en gebruik van woord>

In voorbeelde (3b-e) is daar 'n verryking van herkomsaanduiders deur middel van bykomende aanduiderdele, wat lei tot komplekse herkomsaanduiders. Alhoewel dit voorbeelde is van verskillende grade van verryking in terme van die aantal verrykende aanduiderdele, vertoon hierdie voorbeelde steeds data-homogene verryking wat gerig is op 'n enkele aanduider. Hierdie voorkoms van verryking is beperk tot 'n enkele mikrostrukturele gleuf van 'n woordeboekartikel.

Verrykingsprosedures se toepassing oorskry die verryking van enkele aanduiders. Artikelgleuwe wat 'n spesifieke tipe data bevat, kan verryk word deur die insluiting van nog 'n aanduider wat dieselfde tipe data verstrek. 'n Voorbeeld van hierdie verryking, dit wil sê, dubbele of meervoudige homogene aanduiderverryking, is die insluiting van een of meer sinonieme in 'n bepaalde semantiese kommentaar of semantiese subkommentaar, na afloop van die betekenisparafrase. Die definisie en die sinoniem(e), oftewel die verrykende aanduider(s), bied semantiese data aan, maar elkeen van hierdie inskrywings verteenwoordig 'n afsonderlike aanduider. Vergelyk die volgende voorbeeld uit die Handwoordeboek van die Afrikaanse Taal (HAT):

ek$\cdot k e \cdot r i g ~ b . n w ., b w$.

wat die eie persoon altyd eerste stel of steeds na homself verwys; selfsugtig, egoïsties

Die semantiese kommentaar bevat die definisie en word verryk deur die toevoeging van twee sinonieme, naamlik selfsugtig en egoïsties. Artikelgleufverryking kan ook van 'n dataheterogene aard wees. Dit lei tot die toevoeging van aanduiders van 'n ander datatipe as die verstektipe wat in die bepaalde artikelgleuf aangebied word. 


\section{Data-heterogene verryking}

Verskillende tipes data-heterogene verryking kan gebruik word om die data-oordrag in 'n gegewe woordeboek te verbeter. Hierdie soort verryking kom voor waar 'n gegewe artikelgleuf gebruik word om aanduiders te huisves wat verskillende datatipes aanbied.

Die volgende voorbeeld uit HAT illustreer die verstekmanier waarop 'n lemmateken wat 'n monosillabiese woord verteenwoordig, aangebied word. Die lemmateken werk in (5) beset die gegewe artikelgleuf, dit wil sê, die gleuf vir die gidselement van die artikel en die inligting wat aan hierdie gleuf onttrek kan word, is die spelling van die woord werk:



In die insluiting van twee- en meersillabiese woorde bied hierdie woordeboek ook leiding oor hoofklem en sillabeverdeling. Hierdie tipe leiding sou in 'n afsonderlike artikelgleuf aangebied kon word maar die leksikograaf kan ook vir 'n vorm van teksverdigting kies met die hoofklem en die sillabeverdeling in dieselfde artikelgleuf as die ortografiese data. Die volgende voorbeeld uit HAT illustreer so 'n werkswyse:

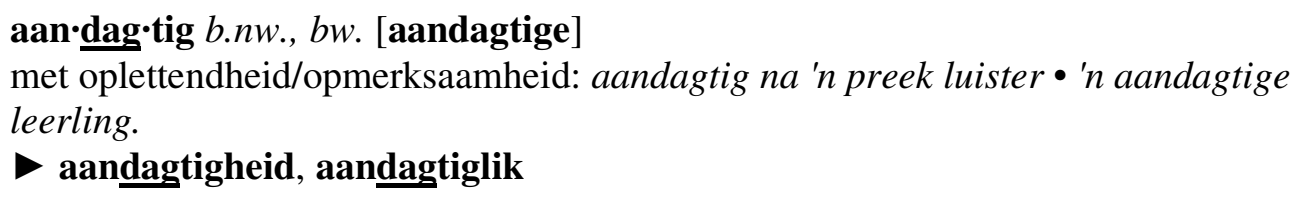

Die gleuf wat die lemmateken aandagtig bevat, is die teiken van twee prosedures van verryking en dit lei tot 'n heterogene data-aanbod in een artikelgleuf. As lemmateken dra aandagtig op mikrostrukturele vlak slegs by tot die oordrag van ortografiese data. 'n Inskrywing aandagtig as lemmateken is 'n onverrykte aanduider. In die voorkoms van datahomogene verryking word al die verrykingsinskrywings uiteindelik deel van een aanduider, naamlik die verskillende betekenisaanduiders in (2) en die verskillende herkomsaanduiders in (3). Aanduiderdele en nie volle aanduiders nie, het deelgeneem aan die verrykingsproses wat in (2) en (3) tot die vorming van komplekse, meerdelige aanduiders gelei het. Die bewerking van die lemmateken aandagtig in voorbeeld (6) illustreer 'n prosedure van dubbele dataheterogene verryking. Die een fase van die verrykingsprosedure voeg 'n aanduider toe wat die sillabe wat hoofklem kry, merk. Die lemmateken word gevolglik weergegee as aandagtig. 'n Volgende fase in die verryking voeg merkers toe wat die woord in sy verskillende sillabes verdeel; die lemmateken word gevolglik weergegee as aan·dag tig. Die vorm aan·dag.tig is 'n komplekse vorm wat die gevolg is van prosedures van sowel teksverdigting as verryking.

Wiegand (1989:427) maak 'n geldige onderskeid tussen aanduiders en merkers as synde die belangrikste klasse funksionele tekssegmente in woordeboeke. 'n Aanduider is 'n tekssegment waaraan die gebruiker inligting kan onttrek oor die onderwerp van 'n betrokke woordeboek. Dit sluit onder andere in betekenis-, uitspraak-, morfologie- en herkomsaanduiders. Merkers is tekssegmente wat help in die identifisering van aanduiders sodat 'n vinniger onttrekking van inligting moontlik is. 'n Onderskeid word gemaak tussen tipografiese en nie-tipografiese 
merkers. Die gebruik van kursief, vetdruk, romeins ensovoorts, is tipiese maniere waarop merkers aangewend word.

Die lemmateken aandagtig is 'n aanduider wat die ortografie van die woord verstrek. Die klemmerker is 'n funksionele tekssegment aan hand waarvan die gebruiker inligting oor die hoofklem van die woord kan onttrek. Dit word daarom ook beskou as 'n aanduider. Dieselfde beginsel geld ook die sillabeverdelingsmerkers aangesien spesifieke inligting aan hierdie inskrywings onttrek kan word. Die oorspronklike inskrywing in die artikelgleuf in voorbeeld (6) is deur ' $n$ tweede en ' $n$ derde aanduider verryk. Hier is die verrykingsinskrywings aanduiders en nie aanduiderdele nie en die komplekse verrykte aanduider bevat draers van verskillende datatipes wat deel het aan die verrykingsprosedure.

Die bestek van die term verryking moet gevolglik uitgebrei word. Die prosedure is naamlik nie altyd slegs gerig op die kern van 'n gegewe aanduider, soos in voorbeeld (1), nie maar kan ook gerig wees op 'n gegewe artikelgleuf. Die data-aanbod binne daardie gleuf kan gevolglik uitgebrei word deur dit te verryk met bykomende aanduiders van óf dieselfde óf 'n ander datatipe.

In voorbeeld (6) (aan.dag.tig) is daar 'n verrykte artikelgleuf waar hoofklem- en sillabeverdelingverryking tot die verstek aanduideraanbieding toegevoeg is. Die volgende voorbeeld illustreer nog 'n tipe data-heterogene verryking:

$\underline{\text { middel }^{2}}$ s.nw. [middels]

1 wat aangewend word om 'n siekte te bestry; geneesmiddel: ' $n$ Middel teen verkoue. •

Heuning en borsdruppels is 'n goeie middel vir' $n$ slegte bors.

2 [middele] wat gebruik word om 'n sekere doel te bereik, tot iets te geraak: Die middele waarvan 'n lening geld kry.

3 [middele] geld, besittings, aardse goedere: Hy beskik oor genoeg middele om so 'n onderneming te finansier. • ' $n$ Middel van bestaan. • Geldmiddele

In hierdie artikel uit HAT bevat die gleuf vir die vormkommentaar 'n aanduiding van die meervoudsvorm van die woord middel. Hierdie lemma verteenwoordig 'n polisemiese leksikale item en dieselfde meervoudsvorm geld nie in al die verskillende betekenisonderskeidings nie. In betekenisonderskeidings 2 en 3 is die korrekte meervoudsvorm middele en nie middels nie. Die bewerking van die eerste betekenisonderskeiding is in die eerste semantiese subkommentaar en hierdie gleuf word voorafgegaan deur die syfer "1" as polisemiemerker. Die syfers "2" en "3" merk die gleuwe waarin die tweede en derde betekenisonderskeidinge behandel word - elk in sy eie semantiese subkommentaar. In albei hierdie artikelgleuwe word die verstekinskrywing van 'n semantiese subkommentaar, naamlik die betekenisparafrase, aangevul deur nog 'n inskrywing, naamlik ' $n$ aanduider wat die meervoudsvorm van die lemmateken bied. Die verskillende meervoudsvorme kon albei in die vormkommentaar van die artikel verstrek gewees het met 'n duidelike aanduiding van hulle bestek, byvoorbeeld:

$\underline{\text { mid } \cdot \text { del }^{2} \text { s. } n w . ~[m i d d e l s ~(b e t . ~ 1) ; ~ m i d d e l e ~(b e t . ~ 2, ~ 3)] ~}$

So 'n aanduiding sou weliswaar tot 'n prosedure van afstandsadressering tussen die meervoudsaanduider wat vir die tweede en derde betekenisonderskeiding van die woord geld en die tersaaklike semantiese subkommentare gelei het. Die huidige aanbieding is 'n 
voorbeeld van twee morfologies verrykte semantiese subkommentare wat telkens verdig word tot 'n semantiese en vormsubkommentaar, met 'n onmiddellike adressering tussen die meervoudsaanduider en die lemmateken vir die spesifieke betekenisonderskeidings.

Pragmaties verrykte artikelgleuwe kom algemeen in woordeboeke voor en hierdie prosedure word ook deur middel van leksikografiese etikette uitgevoer. 'n Etiket se bestek sluit dikwels al die optredes van die lemma in, soos blyk uit voorbeeld (9):

bar·ca·rol-le s.nw. [barcarolles] (Italiaans, musiek)

1 lied wat tradisioneel deur Venesiaanse gondeliers gesing is.

2 musikale komposisie in die styl van so 'n lied.

[<Italiaans barcaruolo bootsman, barca boot]

In hierdie voorbeeld verskyn die etikette Italiaans en musiek in 'n artikelgleuf wat tipies deur etikette met 'n lemmatiese adressering beset word. Die plasing van die etikette in hierdie voorbeeld impliseer dat dit die optrede van die woord barcarolle in al sy betekenisonderskeidinge geld. In voorbeeld (10) verskyn die etiket nie in 'n gleuf voor die betekenisparafrases nie maar ' $n$ afsonderlike etiket verskyn in elke semantiese subkommentaar wat 'n ander polisemiese optrede van die lemma verteenwoordig.

\section{$\underline{\text { bal } \cdot \text { sem }}$}

O s.nw.

1 (botanie) welriekende hars deur plante afgeskei.

2 [balsems] (medies) salf: ' $n$ helende balsem vir drö̈, seer lippe.

$\mathbf{3}$ (figuurlik) iets wat smart/droefheid/teleurstelling versag: Haar vertroostende woorde was soos balsem vir my. • balsem in ' $n$ wond giet (=iets onaangenaams versag.)

Etikette bied pragmatiese leiding en in hierdie artikel is elke semantiese subkommentaar waarin 'n spesifieke betekenisonderskeiding van die lekskale item wat deur die lemmateken verteenwoordig word, behandel word - pragmaties verryk deur middel van 'n etiket.

\section{Tweetalige woordeboeke}

Vertaalekwivalente, dit wil sê, die doeltaalvorme wat 'n gegewe brontaalvorm in 'n gegewe optrede kan vervang, bly die dominante inskrywingstipe in die artikels van tweetalige woordeboeke. Een van die tradisionele probleme in hierdie soort artikels is die onvoldoende aanbiedingswyse wat in talle woordeboeke gevolg word. Vertaalekwivalente moet op so 'n manier aangebied (en selfs bewerk) word dat dit die teikengebruiker in staat stel om inligting op 'n optimale wyse te onttrek. Die teikengebruiker moet verder seker kan wees dat sy/haar keuse van 'n vertaalekwivalent die mees gepaste is vir die spesifieke omgewing waar die woord gebruik moet word. Die gebruik van syfers om tussen die verskillende semantiese subkommentare te onderskei, is reeds 'n belangrike hulpmiddel om die probleem van ekwivalentonderskeiding te help oplos. Vergelyk in hierdie verband voorbeeld (11) hieronder, geneem uit die Oxford Afrikaans-Engels/ English-Afrikaans Skoolwoordeboek/ School Dictionary: 




Die leksikografiese funksie van 'n woordeboek speel ' $n$ bepalende rol in die keuse van aanduiders wat in 'n semantiese subkommentaar ingesluit moet word. In die geval van 'n teksproduksiefunksie is dit noodsaaklik dat die tersaaklike koteksinskrywings, dit wil sê gebruiksvoorbeelde, verstrek moet word. 'n Teksresepsiefunksie vereis 'n minder omvattende bewerking maar die gebruiker moet steeds 'n ingeligte besluit kan maak wanneer 'n gepaste vertaalekwivalent gekies moet word. 'n Blote lysting van vertaalekwivalente, geïsoleer van kotekstuele en kontekstuele data, is meestal tot nadeel van die tipiese woordeboekgebruiker. Ongelukkig straf te veel tweetalige woordeboeke nog hulle gebruikers met so 'n lysting van vertaalekwivalente sonder ' $n$ aanduiding van enige, of ten minste voldoende, gepaste konteksleiding, dit wil sê, leiding t.o.v. die pragmatiese omgewing, en/of koteksleiding, oftewel leiding t.o.v. die sintaktiese omgewing. Die volgende voorbeeld uit die Groot woordeboek/Major dictionary, 'n woordeboek wat vir sowel teksproduksie as teksresepsie gebruik word, bevat 'n vertaalekwivalentparadigma wat volkome wees gelaat is wat ondersteunende inskrywings betref:

(12) op'sigter, (-s) custodian, caretaker; overseer; clerk of works; conservator; checker; green-ranger; keeper; groundsman; banksman; gaffer; ganger.

Elke vertaalekwivalent wat ' $\mathrm{n}$ afsonderlike betekenisonderskeiding voorstel van die leksikale item wat deur die lemmateken verteenwoordig word, behoort tot 'n afsonderlike semantiese subkommentaar. Die woordeboek waaruit (12) geneem is, bevat verskillende tipes mikrostrukture, onder meer rudimentêre, primitiewe, geïntegreerde en nie-geïntegreerde mikrostrukture (vgl. Wiegand 1989, 1996, Gouws 2003, Gouws en Prinsloo 2005). Daar is egter geen sistematiese gebruik van hierdie mikrostruktuurtipes, en geen nakoming van die voorspelbaarheidskriterium nie. Gevolglik kan die gebruiker wat meer as net 'n vertaalekwivalent nodig het om 'n oplossing vir 'n bepaalde probleem te kry, maar net hoop dat die artikel wat hy/sy naslaan die tipe mikrostruktuur vertoon wat 'n ondubbelsinnige keuse van 'n vertaalekwivalent moontlik maak. Artikels soos dié van die lemmateken opsigter met sy rudimentêre mikrostruktuur vereis 'n verrykingsprosedure om 'n beter inligtingsonttrekking moontlik te maak. In die artikel verskaf in (13), geneem uit dieselfde woordeboek as (12), is 'n aantal pragmatiese aanduiders ingesluit in die semantiese subkommentare. Hierdie verryking verseker duidelik 'n beter ekwivalentkeuse:

(13) $\quad \operatorname{los}^{2},(w)$ (ge-) fire (shot); redeem (pledge); ransom (captive); claim (goods); discharge (load); unload (ship), ...

In die geval van (13) het verryking tot verrykte artikelgleuwe gelei. In die artikel in (13) is die verrykingsinskrywings kontekstuele aanduiders wat die pragmatiese omgewing aandui waarvoor die bepaalde vertaalekwivalent as 'n gepaste keuse beskou kan word. Dit is 'n 
voorbeeld van 'n pragmaties verrykte vertaalekwivalentparadigma met verryking wat plaasvind in elke semantiese subkommentaar.

\section{Tipes verryking}

Die toepassing van verrykingsprosedures mag nie op 'n arbitrêre manier gedoen word nie, maar wel volgens 'n bepaalde werklike doel. Daar kan onderskei word tussen drie verskillende tipes verryking. Die werklike doel van die eerste tipe is om die omvang van die data-oordrag van 'n woordeboek te vergroot terwyl 'n tweede tipe die toeganklikheid van die woordeboek verhoog. 'n derde tipe verryking lewer 'n bydrae tot die leksikografiese funksies van 'n woordeboek. Slegs die gebruik van verryking ter uitbreiding van die leksikografiese funksies word vervolgens bespreek.

\subsection{Funksieverryking}

In die hedendaagse leksikografie mag die belang van leksikografiese funksies nooit onderskat word nie (vgl. onder meer Tarp 2000). Verrykingsprosedures moet ook in ag geneem word wanneer daar oor die voorgenome funksies van 'n woordeboek besin word. In die beplanning van enige woordeboek moet die leksikograaf vroegtydig weet watter leksikografiese funksies deur die betrokke woordeboek vervul moet kan word. In hierdie verband is dit belangrik om uitsluitsel daaroor te hê of 'n bepaalde woordeboek 'n mono-, bi- of multifunksionele benadering gaan volg. Dit word nie in die huidige artikel bespreek nie. Ter sake is dat 'n verrykingstoepassing ook tot 'n funksieverryking mag lei, m.a.w. deur ' $n$ spesifieke aanduider in 'n woordeboekartikel te verryk, kan 'n bepaalde leksikografiese funksie bevredig word.

'n Woordeboek soos die eentalige verklarende HAT is veral op die bevrediging van kommunikatiewe funksies gerig met 'n fokus op sowel teksresepsie (veral in die betekenisparafrases) as teksproduksie (veral in die voorbeeldsinne). Ter wille van die verstaan van die woord Nobelprys sou die volgende definisie verstrek kon gewees het:

(14) No·bel-prys $s . n w$.

enigeen van 'n aantal geldpryse jaarliks toegeken aan uitblinkers op verskillende gebiede van die kuns en wetenskap: ...

So 'n definisie sou 'n teksresepsiebehoefte kon bevredig en dus 'n teksresepsiefunksie suksesvol kon vervul. Om bykomende leiding aan die gebruiker te verskaf, het die leksikograaf die betekenisaanduider verryk met 'n aanduiderdeel wat data toevoeg sodat daar ook 'n kognitiewe funksie vervul kan word; dit word geïllustreer in (15):

No·bel-prys $s . n w$.

enigeen van 'n aantal geldpryse jaarliks toegeken uit die nalatenskap van die Sweedse uitvinder van dinamiet, Alfred Nobel, aan uitblinkers op verskillende gebiede van die kuns en wetenskap: ...

Die kundige leksikograaf is in die posisie om verskillende verrykingsprosedures toe te pas sodat die nodige data-aanbod verstrek kan word. Die gebruik van leksikografiese tekskassies (vgl. Gouws en Prinsloo 2010), kan as so 'n prosedure toegepas word. Dit is reeds vroeër genoem dat verryking gerig kan wees op 'n aanduider of op 'n artikelgleuf, maar dit kan ook op 'n volle artikel of selfs die woordeboek as 'n geheel gerig wees. Woordeboekartikels word dikwels verryk deur die toevoeging van bykomende artikelgleuwe, op grond van die 
leksikograaf se oordeel dat die teikengebruikers in 'n bepaalde gebruiksituasie bykomende hulp nodig het. Woordeboeke maak soms ook van tekskassies gebruik om oplossings vir sekere teksproduksieprobleme te bied. Die tekskassie in die volgende voorbeeld uit die HAT Afrikaanse Skoolwoordeboek lei tot 'n teksproduksie-funksieverrykte artikel:

\section{hạ.kie s.nw. [ s] id 'n klein haak, veral een wat in 'n ogie haak om twee dele van 'n kle= dingstuk bymekaar te hou. 2 [mv.] die ronde, vierkantige of krullerige lyntjies wat by skoyf om 'n gedeelte van ' $n$ woord of sin geplaas word: ' $n$ letter/woord/frase tussen hakies plaas. $\diamond$ tussen hakies... Ek sê die vol= gende sommer terloops. $\rightarrow$ HA.,.}

\section{GEBRUIK}

Let op: 'n Mens skryf woorde tussen hakies [NIE in hakies NIE].

\section{Ter afsluiting}

Leksikograwe moet verskillende prosedures aanwend om die gehalte van hulle woordeboeke te verbeter. Metaleksikografiese navorsing mag nie van die leksikografiepraktyk geïsoleer wees nie en maak voorsiening vir die beskrywing van 'n verskeidenheid prosedures waarop die praktiserende leksikograaf hom/haar mag beroep. Ongelukkig is talle prosedures van die leksikografiese praktyk nog nie doeltreffend in die teoretiese leksikografie beskryf nie. Die teoretiese leksikografie moet verder ook vernuwend werk om voorstelle te maak en te beskryf wat volgens die eise van die praktyk geïmplementeer kan word. Verryking is 'n ou prosedure maar 'n verfynde beskrywing daarvan en 'n uitbreiding van die bestek daarvan kan nuwe moontlikhede vir sowel die metaleksikografiese gesprek as die leksikografiepraktyk skep. 'n Meer gefokusde teoretiese benadering tot hierdie prosedure kan praktiese leksikograwe verryk in hulle pogings om beter woordeboeke saam te stel.

\section{Verwysings}

Bergenholtz, H. en R.H. Gouws. 2007. Korrek, volledig, relevant. Dit is die vraag aan leksikografiese definisies. Tydskrif vir Geesteswetenskappe 47(4): 568-586.

Bläsi, C. 1998. Artikel kleiner Lexika über Personen. Ein exemplarischer Vorsto $\beta$ in die angewandte Metalexikographie sachlexikographischer Werke. Doctoral dissertation, Heidelberg University.

Chambers-Macmillan South African School Dictionary. Junior Primary = Nesbitt, R. (ed.) 1996. Manzini: Macmillan.

Gouws, R.H. 2001. Lexicographic training: approaches and topics. In J. Du P. Emejelu (ed.) Elements de Lexicographie Gabonaise. Tome I. New York: Jack Hillman Publishers. pp. 58-94.

Gouws, R.H. 2001a. Der Einfluß der neueren Wörterbuchforschung auf einen lexikographischen Gesamtprozeß und den lexikographischen Herstellungsprozeß. In A. Lehr en H.E. Wiegand (eds). Sprache im Alltag. Berlin: De Gruyter. pp. 521-531. 
Gouws, R.H. 2003. Aspekte van mikrostrukturele verskeidenheid en inkonsekwentheid in woordeboeke. Lexikos 13: 92-110.

Gouws, R.H. and D.J. Prinsloo. 2005. Principles and Practice of South African Lexicography. Stellenbosch: SunMedia.

Gouws, R.H. and D.J. Prinsloo. 2010. Thinking out of the box - perspectives on the use of lexicographic text boxes. In A. Dykstra and T. Schoonheim (eds). Proceedings of the

XIV Euralex International Congress. Leeuwarden: Fryske Akademy. pp. 501-511.

Groot woordeboek/Major dictionary. 14de uitgawe = Eksteen, L.C. (red.) 1997. Kaapstad: Pharos.

$H A T=$ Odendal, F.F. en R.H. Gouws (reds.) 2005. Verklarende handwoordeboek van die Afrikaanse taal. Vyfde uitgawe. Kaapstad: Pearson Education.

HAT Afrikaanse skoolwoordeboek = Luther, J. (ed.) 2009. Kaapstad: Pearson Education.

Hausmann, F.J. and H.E. Wiegand. (1989). Component Parts and Structures of Monolingual Dictionaries: A Survey. In F.J. Hausmann et al. (eds). 1989-1991. An International Encyclopedia of Lexicography. Berlin: De Gruyter. pp. 328-360.

Hausmann, F.J., O. Rauchmann, H.E. Wiegand and L. Zgusta (eds). 1989-1991. Wörterbücher. Dictionaries. Dictionnaires. An International Encyclopedia of Lexicography. Berlin: De Gruyter.

Longman Mini English Dictionary = Summers, D. et al. (eds). 2002. Harlow: Pearson Education.

Longman South African School Dictionary. First Edition. = Summers, D. et al. (eds). 2007. Essex: Pearson Education.

New Oxford Dictionary of English = Pearsall, J. (ed.) 1998. New York: Oxford University Press.

Oxford Afrikaans-Engels/English-Afrikaans Skoolwoordeboek/School Dictionary = Hall, M. et al. (reds.) 2007. Kaapstad: Oxford University Press.

Oxford Reference Dictionary = Hawkins, J. (ed.) 1986. Oxford: Clarendon Press.

Random House Dictionary = Stein, J. (ed.) 1980. New York: Ballantine Books.

Shorter English Learner's Dictionary = Christie, B. et al. (eds). 1977. London: Collins.

Tarp, S. 2000. Theoretical challenges to LSP lexicography. Lexikos 10: 189-208.

Wiegand, H.E. 1989. Der Begriff der Mikrostruktur: Geschichte, Probleme, Perspektiven. In F.J. Hausmann, O. Rauchmann, H.E. Wiegand and L. Zgusta (eds). 1989-1991. An International Encyclopedia of Lexicography. Berlin: De Gruyter. pp. 409-462.

Wiegand, H.E. 1996. Das Konzept der semiintegrierten Mikrostrukturen. Ein Beitrag zur Theorie zweisprachiger Printwörterbücher. In H.E. Wiegand (ed.) 1996. Wörterbücher in der Diskussion II. Tübingen: Max Niemeyer Verlag. pp.1-82.

Wiegand, H.E. 2005. Angaben, funktionale Angabezusätze, Angabetexte, Angabestrukturen, Kommentare und mehr. Ein Beitrag zur Theorie der Wörterbuchform. Lexicographica 21: 202-379.

Wiegand, H.E., M. Beißwenger, R.H. Gouws, M. Kammerer, A. Storrer and W. Wolski (eds). 2010. Wörterbuch zur Lexikographie und Wörterbuchforschung/Dictionary of Lexicography and Dictionary Research. Berlin: De Gruyter. 